\title{
2006-341: APPLYING MARKETING PRINCIPLES TO ATTRACTING AND RETAINING ENGINEERING STUDENTS
}

\section{Robert Summers, Weber State University}

Dr. Robert A. Summers is a Full Professor in the Computer \& Electronics Engineering Technology department at Weber State University in Ogden, Utah. He earned his $\mathrm{PhD}$ in electrical engineering from the University of Idaho, where he was also an Associate Professor. His bachelor's degree is from Brigham Young University, and his masters from the University of Washington. Dr. Summers's experience in the engineering field also includes eight years in the aerospace industry, specializing in the design of avionics instrumentation and control systems. Throughout his career in both industry and education, he has worked as a consultant, brought in to solve specific problems with high profile military and NASA projects. His current focus in education is to teach sound engineering principals with a hands-on application.

\section{Julanne McCulley, Weber State University}

Julanne K. McCulley (Julie) earned a bachelor's degree in Electronic Engineering Technology and a second degree in Mathematics Teaching from Weber State University. She has over 15 years of industry engineering experience, specializing in automation and controls in the automotive industry. For three years, Julie taught developmental math courses for Weber State University. She is currently a full time instructor in the Computer and Electronic Engineering Technology Department for the College of Applied Science and Technology at Weber State University. 


\section{Applying Marketing Principles to Attracting and Retaining Engineering Students}

Education and the institutions delivering it have ancient roots and traditions. The mentor/student relationship described in writings of revered scholars and teachers such as Plato and Socrates remain as the ideal for modern pedagogy. Education is driven by requirements. There are requirements for entrance, requirements for exit, requirements for every step between. This often-rigid system of qualified teachers setting up stringent requirements for a desired academic outcome is largely responsible for the enormous body of knowledge our society depends on today. It is not the purpose of this paper to suggest changes to the requirements for qualified engineering degrees. It is to suggest a broader look at how to make these requirements more attractive to today's student in a world with many competitive options.

It is a well-known fact in the field of engineering sciences that enrollment in university engineering and engineering technology programs has declined since the mid 1980's, and that attrition rates, particularly among the freshman class, are high. There have been thousands of studies, but a study by Mary Besterfield-Sacre, Cynthia J. Atman, and Larry J. Shuman entitled Characteristics of Freshman Engineering Students: Models for Determining Student Attrition in Engineering is referenced here. The authors present statistics detailing a $12 \%$ attrition rate nationwide in 1975, an attrition rate of just over $24 \%$ in 1990 , to over $50 \%$ in 1997 . Half of those students dropped out their freshman year. ${ }^{2}$ While there are many causes cited for the decline, and some institutions have had some success in at least maintaining their numbers, the American Society for Engineering Education annual publication of statistics for engineering and engineering technology colleges shows that many of the most prestigious institutions continue to struggle with enrollment. In 2004, Texas A\&M had 400 more seniors enrolled than freshman. Georgia Tech had nearly 300 more seniors than sophomores. ${ }^{1}$

The reasons behind the fall-off are subjects for more comprehensive study, but a few suggestions to look at are the advances in glitzy consumer electronics, which have opened vast career opportunities in arenas of technology not requiring traditional engineering degrees. Secondary schools are likewise experiencing decreased interest in advanced math and science coursework, so the pool of potential engineering students is shrinking. The image of engineering has suffered in media presentations of "geeks" and "nerds" confined to cubicles, disrespected by management and members of the opposite sex. Add to this the opportunities to make significant incomes in careers requiring considerably less scholarly effort, it becomes apparent that engineering must become more competitive in marketing an improved image.

It isn't reasonable to expect engineering departments to either become or employ marketing experts, but basic marketing principles offer some straightforward strategies to consider during the normal course of department meetings and focus groups. Marketing becomes an attitude attached to all department functions rather than an added task. It serves as a criterion for decision-making, not as a limiting filter for decision-making. The principles presented here are a result of some departmental cross-fertilization in a single university with a struggling EET department and a vibrant business department. The following condensation of marketing principles comes from course notes by Anthony Allred, $\mathrm{PhD}$, a full professor in the Goddard School of Business, Weber State University. 
The mainstay of commercial marketing is an organization's SWOT analysis. The acronym stands for Strengths, Weaknesses, Opportunities and Threats. It is a blueprint for an organization's areas to promote and build upon, as well as those areas that need to be addressed for improvement or caution. In short, strengths and weaknesses reside within the organization, and include such things as personnel, facilities, finances, access to technology, internal organization and planning. A SWOT analysis examines all areas of the internal environment and creates a detailed description of where the organization is strong, and where it is weak. Opportunities and threats come from the external environment and include social values, demographic forces, political and legal forces, technological advances, economic and competitive forces, and natural resources or physical factors such as weather events. ${ }^{3}$ An organization has no control over these outside factors, but must surely address them and develop strategies to accommodate them. The SWOT analysis becomes a dynamic document, which changes over time. The value for such a document lies in an organization's ability to focus directly on promoting and capitalizing on strengths and opportunities, while looking for ways to improve their weaknesses, and "watching their backs" for threats.

Once a SWOT analysis has been articulated, a marketing organization searches out its target market. This is particularly important for an engineering department seeking more than just a group of students enrolling and showing up for the first day of class. A marketing segment is a division within the larger group (all qualified high school graduates) which will share specific characteristics and behaviors. ${ }^{3}$ This smaller division will probably contain students with particular aptitudes and interests, indicating the probability of success in engineering. The characteristics of this group can be fairly easily described in a brainstorming session within the department.

Marketers will then create a target market within this segment on which to concentrate their marketing efforts. ${ }^{3}$ Mass marketing is expensive and frequently hit-and-miss. However, defining a narrower target market focuses on specific groups within the segment, and can be extremely effective. For example, there may be a particular area high school with graduates that are especially attractive to an engineering program. An effective marketing approach may succeed in recruiting a higher number of these students. Women are underrepresented in engineering, yet engineering disciplines have many attributes that may be highly appealing to women, and with the correct motivation, women may share equal success with men in these disciplines. A recruiting approach designed to attract women or other minority students as a target market within the market segment may enjoy substantial results.

In the world of business marketing, an important principle is brand recognition. Companies will not spend resources to contact their target markets just to have people forget who and what they represent. Many companies spend a great deal of time and effort to create name recognition, and associate it with an image customers will be able to remember. ${ }^{3}$ It may be an effective and even entertaining strategy for engineering departments as well: to apply a little creativity in developing a name, logo, and mark or symbol representing their product - that engineering degree. The resulting image appears on letterheads, web sites and other recruitment materials to maintain a memorable imprint of every contact the potential student has with the department. It works well in commercial marketing. The principle should translate to educational marketing as well. 
For commercial marketers, the target is called a customer. In education, the student should be considered a customer as well, simply because the student is paying for a product. There are some inherent differences between commercial customers and educational customers, but for the purposes of applying the next principle, market research, a potential customer is a potential purchaser. The purpose for conducting market research is to collect, analyze and interpret data about the customer, competitors, and the environment affecting customer decisions. ${ }^{3}$ This is probably the most important of the principles for engineering departments hoping to solve enrollment and retention dilemmas. It is also the most difficult to implement in terms of time and available resources. The value of obtaining data from the range of social, economic and academic variables affecting personal choices to enter engineering fields is huge. Perhaps graduate committees should be formed, and grant requests written to tackle this monumental task and add the research to the body of information available in the discipline.

The remaining marketing principles involve the product or service itself. In business, the product is defined as the tangible and intangible capacities to satisfy the wants and needs of customers. It is a bundle of features, advantages and benefits to the customer. ${ }^{3}$ The product being offered by an engineering school appears to be much more fundamental - an engineering diploma certifying that a list of requirements has been met. For the most part, that list of requirements cannot be adjusted or modified simply because it doesn't match the "wants and needs" of the customer, or the student. Therein lies the basic difference between the "customer" in business and in academia.

However, some of the criteria by which a commercial product is evaluated might also be applied to the product an engineering student purchases when he or she enrolls in the program. For example, there are ten determinants for evaluating the quality of a commercial sector service. They are reliability, responsiveness, competence, accessibility, courtesy, communication, credibility, security, understanding and tangibility. ${ }^{3}$ Within engineering departments, it may prove a valuable exercise to examine the program's overall service performance in these ten categories. Are the faculty and staff who deliver the service perceived as reliable, responsive, competent, accessible, courteous, credible and able to communicate effectively? Does the student experience a sense of security within the department? Does the student understand the requirements for success in the program at the outset? Does the student have realistic expectations for the tangible rewards awaiting completion of the program? These are product enhancements over which academic departments exercise control. They are adjustable without changing requirements for obtaining the product.

Marketers rely on what they call the 4 P's: product, promotion, price and place. Their plans employ a mix of the 4 P's to convince consumers to purchase. ${ }^{3}$ Engineering departments do not set the price and rarely have anything to say about the place their programs are offered.

However, when it comes to promotion, they should consider these two factors and present them in their best light. Price is essentially a value that is exchanged for something. ${ }^{3}$ In education, price is more than a tuition check. It represents personal effort and sacrifice. The promotional challenge in engineering is to establish that the "something" received in exchange for the money, rigorous mental exercise, and personal sacrifice invested in the program is worth it in the end. There is much work to be done in the area of public relations to overcome some bad press engineering disciplines have received in the past two decades. The scope of this paper is not to 
detail how to do that, but to suggest that the challenge must be tackled if recent trends are to see a reversal. It is a marketing challenge rather than a technical one.

Most marketing challenges require a great deal of time, money, intense strategic planning and even luck to overcome. It would be unrealistic to proclaim that a system wide marketing strategy is a short term solution to complex enrollment and retention problems. However, relatively small changes in the way departments do business, based on the concept of the student as a customer, may have a role in reversing enrollment and retention declines in individual institutions. The balance of this paper presents a case study involving an entry level electronics course in the Computer and Electronics Engineering Technology department at Weber State University, Ogden, Utah.

Historically, the department experienced the ups and downs in enrollment that characterize many educational institutions' responses to economic times. Generally, economic recessions see increased enrollments. In recent years, general enrollment increases in the university were not reflected in the department, raising a flag to dig deeper for explanations. Some probable external causes were mentioned at the beginning of this paper, but further analysis indicated some internal causes as well.

All students entering the CEET program are required to take a two semester hour fundamental electronics course. Some programs outside the department also required the course. Data from course evaluations determined that this was a particularly unpopular course, regardless of the instructor. The department received an edict to revise the course offering. The challenge became one of turning a dreaded tedious course into one that is exciting and motivating without sacrificing content. In order to accomplish that, the curriculum authors looked at the student to determine what he or she wants and needs in a foundation course.

Before accommodating the student, however, the authors surveyed department instructors to determine their requirements for students entering follow-on courses. Interestingly, the existing course was falling short of their requirements as well, so it was failing everyone concerned. The authors created a course concept outline based on instructor feedback.

The authors then compiled a list of features students were likely to find interesting and motivating. First on that list was hands-on activities. Every lesson would include a lab period. Next was highly visual concept support with photos and colorful illustrations. Last, but certainly not least, was comprehensible text. The authors envisioned a course where students could read and understand the concepts on their own before each lesson, then come to the instructor to apply those concepts. Classroom time and instructor interaction would be spent in creative application rather than text interpretation.

Unable to find an existing textbook that met the criteria for the course's preliminary plan, the authors decided to write their own. A CD medium was chosen because it allowed for the required features on a short publishing deadline. The department already had access to and expertise in Macromedia Authorware ${ }^{\mathrm{TM}}$, a powerful publishing program that provides versatility in text presentation, allows imported graphics, and even an audio feature that audio learners appreciate. The entire curriculum package, containing the $\mathrm{CD}$ text, and a kit with lab 
components and materials addresses all learning modalities. Labs, report forms and problem sets are printable from the CD.

The results of designing the curriculum for this course with the benefits to the student a major consideration has had promising results. The course was presented by the authors for the first time Fall Semester, 2004. Subsequent course evaluations indicated a continuing improvement in student attitudes toward the course as indicated in the graph below.

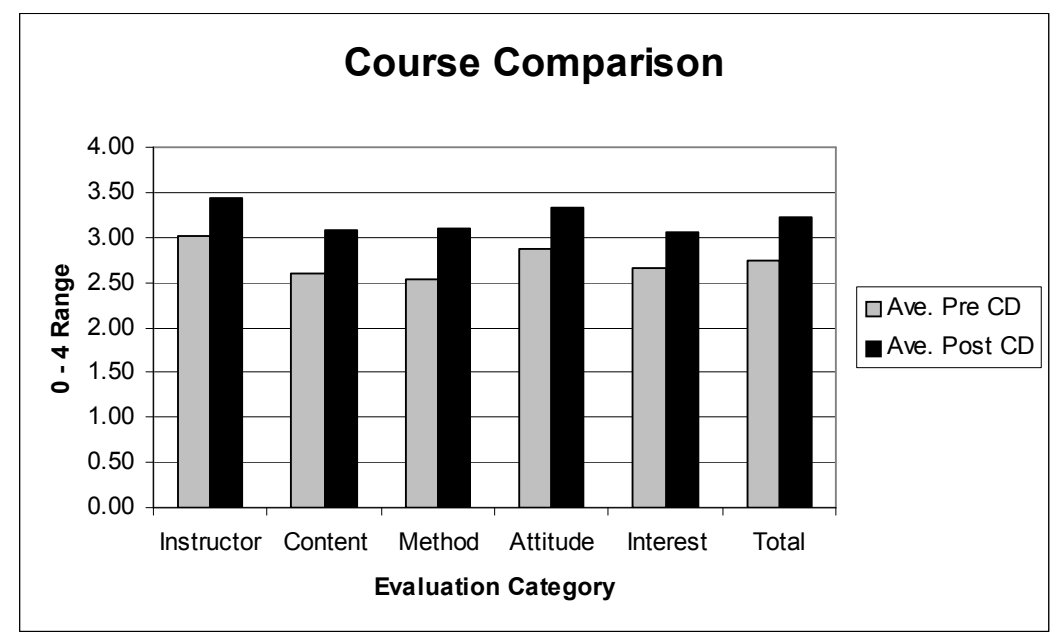

The authors also conducted surveys and solicited student input to further improve the course for the following semester. Using a CD medium allowed for immediate changes. The first semester served as a beta test, and the department paid for the CD's and lab materials. Spring Semester, 2005 , students purchased the package in the student bookstore just like any text. The price for the CD text and all required components and materials was in the range of a hardbound text, and students indicated in the surveys they considered it a good value for the price. It should be noted here that an outside company produced the CD and lab materials package. The department was not involved in purchasing or distribution after the beta test semester.

Beginning with Spring Semester, 2005, the department began compiling data from course evaluations and enrollment to determine if positive student attitudes toward their first university level exposure to electronics would immediately translate to an increase in freshman retention. A normal course progression would take the students into an AC/DC Circuit Design class, so this class was used as the base for plotting the number of students in the entry level course compared with the number enrolling in the follow-on course. Many factors may influence the raw enrollment figures, including overall university enrollment figures, so the value of this data is only useful in looking at the trends in general. Preliminary conclusions indicate that retention, while experiencing peaks and valleys over the past five years, is about the same as in 2001 . Enrollment in the entry-level electronics course also peaks and dips, but overall it does not follow the decline in university enrollment. 

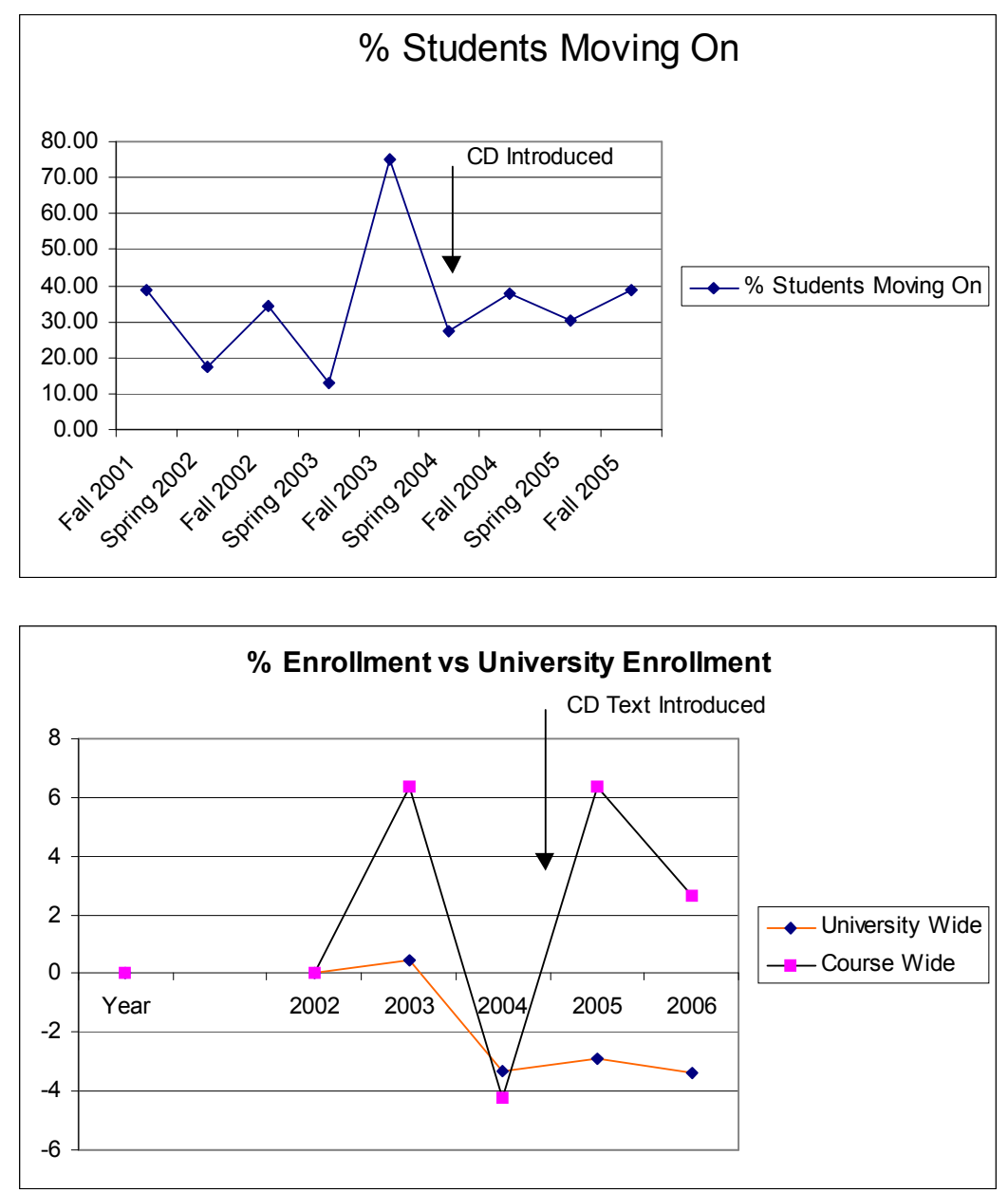

Another area of significant interest is student performance in follow-on EET coursework. There was an informal observation from professors in the CEET department during the Fundamentals introductory year that there was new energy among students in the department. More students were spending time in the labs involved in creative projects. In order to quantify student performance, the department seeks to compare the average grades in subsequent coursework to average grades coming out of the old curriculum. With only two semesters of grade data available, it is too soon to form conclusions on student performance throughout the balance of their EET program. A simple grade comparison over two semesters between students moving from the Fundamentals course to the AC/DC Circuit Design course shows no statistical grade difference between the Fundamentals group and their counterpart group, who either took the course prior to Fall, 2004, or transferred in from other institutions.

While not dramatic, the initial data suggests that even one course improvement has a positive impact on enrollment, if only to maintain the numbers while other programs are losing students. Developing courseware that is engaging, comprehensible, and appealing to students does not require a sacrifice in content. It does require a change in direction for entry-level course developers to assess the wants and needs of the $21^{\text {st }}$ Century student from a marketing perspective. We must make the field attractive to prospective entrants, even to moving marketing strategies into the high school level. 
The need for the United States to interest and train talented young people in the engineering sciences is urgent. Looming problems in our use of natural resources, food production, waste disposal, production and distribution of energy, environmental pollution, national defense, dealing with climactic changes, and maintaining and distributing our growing reservoir of information may threaten our way of life without engineering solutions. Technical problems are not solved by actors and artists and social reformers, but by those who know how to apply scientific principles and technology. At this time in history, society should be doing everything possible to attract these people, and to reward them for their dedication and talent in technical problem solving. The average person on the street has a blind faith that the scientific community will come through as they always have in the past, but it will not happen unless we continue to attract and train our best and brightest to solve these problems. By employing the same principles that business uses to sell their products, we must sell engineering to potential students, and convince the community in general that the need is real.

1. American Society for Engineering Education (ASEE), Profiles of Engineering and Engineering Technology Colleges, 2004 Ed.(Washington DC, ASEE, 2005).

2. Besterfield-Sacre, Mary, Atman, Cynthia J. and Shuman, Larry J., "Characteristics of Freshman Engineering Students: Models for Determining Student Attrition in Engineering", Journal of Engineering Education,(April, 1997) Vol 86, No. 2.

3. Solomon, Michael R., Stuart, Elnora W., Marketing: Real People, Real Choices, $3^{\text {rd }}$ Ed. (New Jersey, Pearson Education, Inc. 2003). 